\title{
Sleep and immune function
}

\author{
Luciana Besedovsky • Tanja Lange • Jan Born
}

Received: 12 August 2011 /Revised: 13 October 2011 / Accepted: 14 October 2011 / Published online: 10 November 2011

(C) The Author(s) 2011. This article is published with open access at Springerlink.com

\begin{abstract}
Sleep and the circadian system exert a strong regulatory influence on immune functions. Investigations of the normal sleep-wake cycle showed that immune parameters like numbers of undifferentiated naïve $T$ cells and the production of pro-inflammatory cytokines exhibit peaks during early nocturnal sleep whereas circulating numbers of immune cells with immediate effector functions, like cytotoxic natural killer cells, as well as anti-inflammatory cytokine activity peak during daytime wakefulness. Although it is difficult to entirely dissect the influence of sleep from that of the circadian rhythm, comparisons of the effects of nocturnal sleep with those of 24 -h periods of wakefulness suggest that sleep facilitates the extravasation of $T$ cells and their possible redistribution to lymph nodes. Moreover, such studies revealed a selectively enhancing influence of sleep on cytokines promoting the interaction between antigen presenting cells and $\mathrm{T}$ helper cells, like interleukin-12. Sleep on the night after experimental vaccinations against hepatitis A produced a strong and persistent increase in the number of antigen-specific Th cells and antibody titres. Together these findings indicate a specific role of sleep in the formation of immunological
\end{abstract}

This article is published as part of the Special Issue on Sleep.

Luciana Besedovsky and Tanja Lange contributed equally to this work.

L. Besedovsky $\cdot$ T. Lange $\cdot$ J. Born

Department of Medical Psychology and Behavioral Neurobiology, University of Tübingen,

Tübingen, Germany

L. Besedovsky $\cdot$ T. Lange $\cdot$ J. Born $(\square)$

Department of Neuroendocrinology, University of Lübeck,

Ratzeburger Allee 160,

23538 Lübeck, Germany

e-mail: born@kfg.uni-luebeck.de memory. This role appears to be associated in particular with the stage of slow wave sleep and the accompanying proinflammatory endocrine milieu that is hallmarked by high growth hormone and prolactin levels and low cortisol and catecholamine concentrations.

Keywords Sleep · Circadian · Immune · Cytokines · Neuroimmunology $\cdot$ Inflammation

\section{Introduction}

Over the last 15 years, research following a systems approach of neuroimmunology has accumulated surprisingly strong evidence that sleep enhances immune defence, in agreement with the popular wisdom that 'sleep helps healing'. Although the communication between sleep regulatory networks in the central nervous system and the cells and tissues of the immune system is basically bidirectional, in this review, we will focus on the role of sleep for proper functioning of the immune system. First, we will give a short overview of the signals which mediate the communication between the nervous and immune system and thus provide the basis for the influence of sleep on immune processes. Because normally sleep is embedded in the circadian sleep-wake rhythm, we will then review studies that examined immune changes associated with the sleep (or rest) phase of this rhythm, without attempting to isolate the effects of sleep per se from those of circadian rhythm. Thereafter, we will concentrate on studies that aimed at disentangling the immuno-supporting effects of sleep from those of the circadian system. Results from these studies, many of them comparing the effects of sleep during the normal rest phase with $24 \mathrm{~h}$ of continuous waking, support the view that sleep is particularly important for 
initiating effective adaptive immune responses that eventually produce long-lasting immunological memory. We will close with some remarks about the detrimental effects of prolonged sleep loss on immune functions showing the importance of proper sleep for general health.

\section{Shared signals and key players}

Neuroimmune interactions are based on specific anatomical and physiological conditions: (1) Neurons, glia cells and immune cells share intercellular signals like hormones, neurotransmitters and modulators, cytokines and chemokines, and they express respective receptors for these signals $[4,94]$. (2) Some of these shared signals can cross the blood-brain barrier in both directions $[18,28]$. (3) Immune cells traffic to all sites throughout the body, come in close contact to nerve endings and to the brain at the meningeal borders and in the cerebrospinal fluid and can even reach the brain parenchyma [98, 101]. (4) Primary lymphatic tissues (thymus and bone marrow) and secondary lymphatic tissues (spleen, lymph nodes, mucosa-associated lymphatic tissue) are innervated by sympathetic, peptidergic and partly also by sensory nerve fibres [89, 90]. (5) The endocrine and autonomous nervous systems regulate immune functions not only directly via hormones and neural innervation, but also indirectly via influences on blood flow, blood pressure, lymph flow [80, 90], the supply of substrates like glucose, fatty acids and oxygen [5, 44, $114]$ and on non-immune cells in the vicinity of lymphatic tissues like adipocytes surrounding the spleen and lymph nodes $[62,70]$. Note that the conceptual borders between hormones, neurotransmitters, cytokines and chemokines are blurred. For example, norepinephrine is a hormone released from the adrenal glands and also a neurotransmitter in the central nervous system; leptin acts as a circulating hormone but also as a paracrine cytokine signal.

The cellular key players in the immune system are leukocytes (white blood cells) that can be differentiated according to their ontogenetic development (innate vs. adaptive), their hematopoietic lineage (myeloid vs. lymphoid), their site of maturation (thymus - $\mathrm{T}$ cells vs. bone marrow-B cells) and their site of primary action (e.g. in lymph nodes-naïve and central memory $\mathrm{T}$ cells vs. peripheral tissues - effector memory and effector T cells), their antigen specificity (unspecific-cells of myeloid origin, natural killer (NK) cells and plasmacytoid dendritic cells (pDC) vs. antigen-specific - $\mathrm{T}$ and $\mathrm{B}$ cells), their function (e.g. T helper (Th) cells, cytotoxic $\mathrm{T}$ lymphocytes (CTL), NK cells, regulatory T cells, antigen presenting cells (APC), memory cells) and their cytokine profile (e.g. Th1, Th2, Th17). Phenotyping is based on cell structure (size, shape of the nucleus, granularity), on surface markers that are numbered according to the cluster of differentiation (CD) and on the pattern of cytokines that are released spontaneously or upon stimulation in vivo or in vitro.

All these cells serve immune defence, i.e. the detection and elimination of molecules and cells that bear foreign antigens, altered self-antigens or-in a broader sense-that indicate cellular damage and therefore danger [47, 51]. Figure 1 illustrates the most important steps of an adaptive immune response to infection: Invading antigen is taken up by APC (macrophages, DC, B cells) that are attracted to the site of intrusion by 'danger signals', i.e. signals that are released locally due to tissue injury. APC then migrate to the draining lymph node via afferent lymphatics and present the antigen to Th cells with the respective $\mathrm{T}$ cell receptor to form the 'immunological synapse' [49]. Th cells become activated, proliferate and differentiate, e.g. into Th1 or Th2 cells, thereby producing a progeny of thousands of antigen-specific Th cells. They help B cells to become antibody producing plasma cells and leave the lymph node after several days to support macrophages and CTL in eliminating the pathogen. Some of the antigen-specific Th cells, CTL and B cells survive and represent the immunological memory which allows for a faster and more efficient immune response once the antigen is re-encountered. Balanced regulation is of utmost importance in this multi-step process - immune activation should be sufficient, but locally limited and should not lead to over-shooting systemic inflammation. This is achieved by tight safety measures such as the restriction of immune activation by major histocompatibility complexes, the need of co-stimulatory signals for an effective response and counter-regulatory signalling as established, for example, by the mutually inhibitory actions of provs. anti-inflammatory and $\mathrm{Th} 1 \mathrm{vs}$. Th2 signals, by regulatory $\mathrm{T}$ cells and during apoptosis (programmed cell death). A failure of these mechanisms can lead to immunodeficiency on the one hand or septic shock, allergy and autoimmunity on the other hand.

Comparing the immune and the central nervous system (CNS), both systems share a basic feature, i.e. they both respond to external stimuli and generate memory in a multistep process that involves cell to cell contacts (synapses) [66]. The different stages of memory operations in the CNS are usually divided into an encoding phase, a consolidation phase in which the information is transferred from a shortterm to a long-term store (with both stores represented by different neuronal networks) and a recall phase. This division might in its basic features also hold true for the different stages of immunological memory: According to this proposition, the encoding phase would in the immunological context be represented by the uptake of the antigen (the information which is to be remembered) by APC. The consolidation phase, in which, in the CNS, the crucial information of the newly encoded memory is 


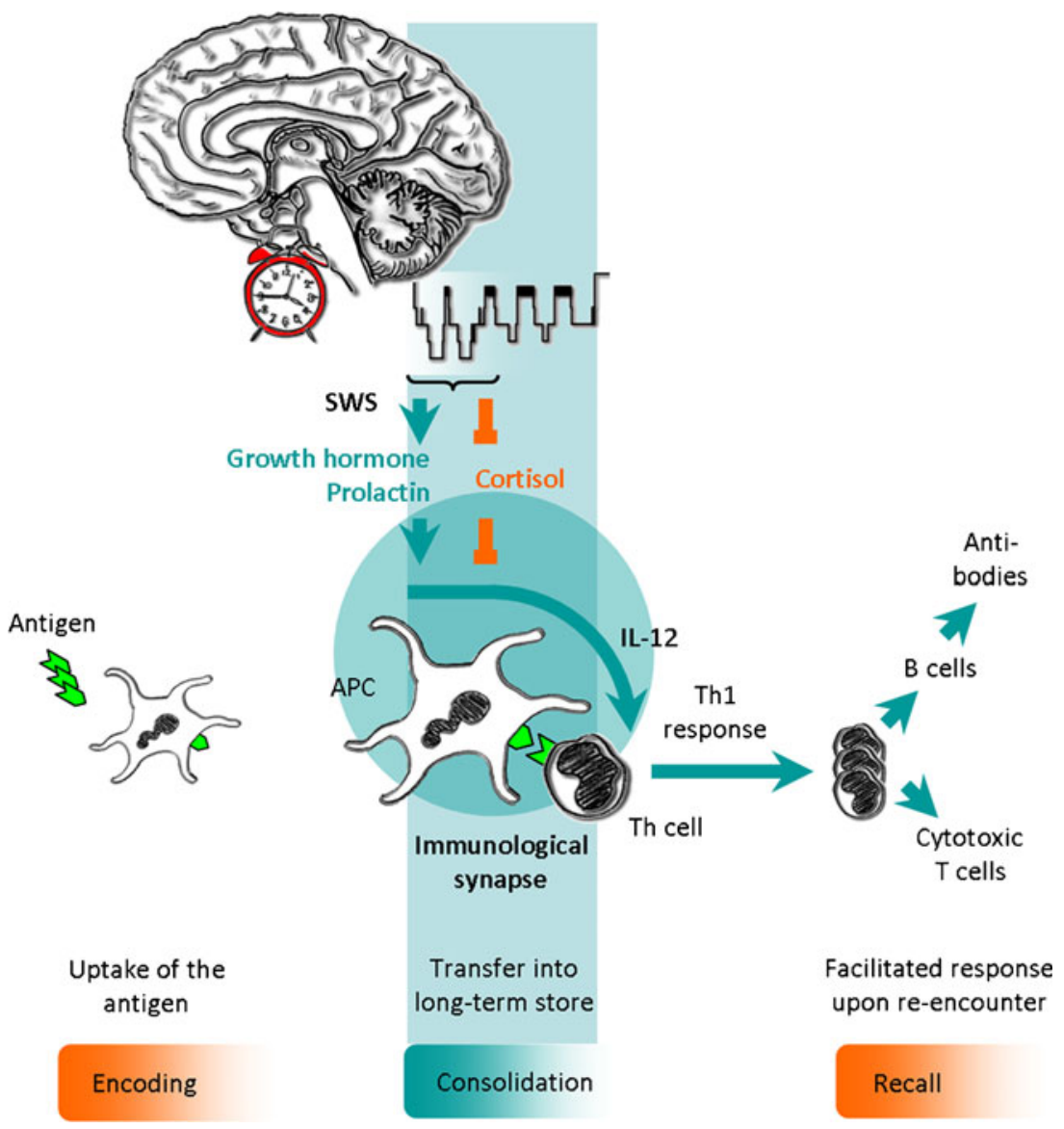

Fig. 1 Concept: Sleep supports the initiation of an adaptive immune response. The invading antigen is taken up and processed by antigen presenting cells $(A P C)$ which present fragments of the antigen to $\mathrm{T}$ helper $(T h)$ cells, with the two kinds of cells forming an 'immunological synapse'. The concomitant release of interleukin (IL)-12 by APC induces a Th1 response that supports the function of antigenspecific cytotoxic $T$ cells and initiates the production of antibodies by $\mathrm{B}$ cells. This response finally generates long-lasting immunological memory for the antigen. Sleep, in particular slow wave sleep (SWS), and the circadian system act in concert to generate a pro-inflammatory

transferred from its temporary storage site to neuronal networks serving as long-term store, might be represented by the formation of the 'immunological synapse' between APC and $T$ cell $[38,49]$, during which the antigenic information is forwarded from a short-term (APC) to a long-term ( $\mathrm{T}$ cell) store. Finally, the recall phase would be represented by the facilitated response of the immune system upon re-encounter of the antigen (Fig. 1). It is clear that this is a pure conceptual view and that there are apparent differences between the two systems (cells of the immune system are migratory and act in special compartments and their proliferative capacity clearly outnumbers that of neurons). Nevertheless, the comparison with concepts of neurobehavioural memory formation which is well known to benefit from sleep [30] might also help in understanding how sleep regulates memory formation hormonal milieu with enhanced growth hormone and prolactin release as well as reduced levels of the anti-inflammatory stress hormone cortisol. The hormonal changes in turn support the early steps in the generation of an adaptive immune response in the lymph nodes. In analogy to neurobehavioural memory formed in the central nervous system, the different phases of immunological memory might be divided in an encoding, a consolidation and a recall phase. In both the central nervous system and the immune system, sleep specifically supports the consolidation stage of the respective memory types. Modified from Lange and Born [71]

during adaptive immune responses. Since sleep specifically enhances the consolidation of neurobehavioural memories whereas encoding and recall usually take place during waking, the transfer of this concept to the immune system would implicate that it is also the consolidation phase of immunological memory formation (that is, the formation of the immunological synapse) which mostly benefits from sleep. Indeed, as outlined in the section 'Sleep enhances the formation of immunological memory', this effectively seems to be the case.

\section{The sleep-wake cycle and immune function}

Life is organised in rhythms. A multi-oscillatory system with cellular clocks in many, if not all cells of the organism 
which are synchronised by a hypothalamic pacemaker, the suprachiasmatic nuclei, regulates the circadian $(\sim 24 \mathrm{~h})$ rhythm of body functions and behaviour. The sleep-wake cycle can be regarded as the most prominent manifestation of the circadian rhythm. Sleep and the circadian system are tightly intertwined (see articles on clock genes and circadian rhythms in this special issue). In most cases, both act in concert to adapt the organism to the ever-changing demands of the solar day and to separate otherwise incompatible body functions in time. Thus, very robust changes are evident during the regular sleep-wake cycle not only with regard to physical and mental activity, cardiovascular function and temperature regulation, but also for immune parameters like leukocyte numbers, function, proliferation and cytokine production. Of note, most of these changes occur in synchrony with the sleepwake cycle regardless of whether the active phase occurs during daytime, like in humans, or during nighttime like in rodents (with one exception, i.e. the release of melatonin). Accordingly, such diurnal changes occurring in immune parameters during the sleep-wake cycle can be categorised into two classes according to their peak times, i.e. rhythms exhibiting their maximum during the rest period and rhythms with a peak during the active period. Before we go into the specific contribution of sleep to immunity, here we discuss the changes in immune cell counts and function as they are normally associated with the regular sleep-wake cycle.

The early resting period represents a pro-inflammatory state

The nocturnal sleep period in humans is characterised by a profound down-regulation of the two stress systems, the hypothalamus-pituitary-adrenal (HPA) axis and the sympathetic nervous system (SNS), with a concomitant drop in blood levels of cortisol, epinephrine and norepinephrine. In contrast, mediators serving cell growth, differentiation and restoration like the pituitary growth hormone $(\mathrm{GH})$ and prolactin and (in day-active humans) the pineal hormone melatonin show a steep increase in their blood levels during sleep [12, 58, 95]. In parallel, increases of leptin that is released by adipocytes are assumed to prevent sleepdisturbing feelings of hunger during this time [103]. Despite their very different cellular sources, GH, prolactin, melatonin and leptin exert remarkably synergistic actions on the immune system. They are pro-inflammatory signals that support immune cell activation, proliferation, differentiation and the production of pro-inflammatory cytokines like interleukin (IL)-1, IL-12, tumour necrosis factor (TNF)- $\alpha$ and of Th1 cytokines like interferon (IFN)- $\gamma$ [7, $37,41,57,58,65,70,77,93]$. In contrast, cortisol and catecholamines generally suppress these immune functions in an anti-inflammatory manner [4, 39], although some specific aspects of immunity may be supported by these signals. Of course, when experimentally administered, the effects of these hormones essentially depend on dosage and timing, and here only acute actions of these hormones within physiological ranges are of relevance. On this background, numerous experiments have shown a consistent and intriguing pattern of endocrine and immune rhythms reflecting an 'inflammatory peak' during nocturnal sleep whereas wakefulness is associated with prevalent anti-inflammatory activity [74, 100, 113].

Peaks of pro-inflammatory and/or Th1 cytokines during the rest period have been observed, often during the early slow wave sleep (SWS)-dominated portion of sleep, in humans as well as in animals on the mRNA and protein level in different tissues including the brain [52, 69], adipose tissue [52] and lymph nodes [41], but also in serum/plasma [17, 52, 79, 113] and in unstimulated as well as stimulated peritoneal and splenic macrophages [59, 64] and peripheral blood cells (Bollinger et al., under revision) [8, 9, 13, 31-33, 73]. Whereas the boost in stimulated cytokine production during the rest period can be explained by the above-mentioned shift towards increased release of hormones with proinflammatory actions $[7,39,41,57,58,65,70,93]$, the question arises why spontaneous cytokine release shows a parallel rhythm. What is it that triggers pro-inflammatory cytokine production throughout the body with the beginning of the rest period? A tentative explanation is that very different factors accumulate during the active wake period which can be collectively termed endogenous 'danger signals' like reactive oxygen species, nucleotides (e.g. adenosine triphosphate) and heat shock proteins (HSP) and are released as a result of very different forms of cellular stress like physical activity, metabolism, synaptic transmission and cell injury. The action of these endogenous danger signals resembles that of exogenous danger signals, i.e. classical immunological stimulants of microbial origin like lipopolysaccharide (LPS), muramyl peptides and other tolllike receptor ligands, in that they stimulate the production of pro-inflammatory cytokines by APC. Pro-inflammatory cytokines in turn exert a positive feedback acting themselves as danger signals and, thus, eventually support the initiation of adaptive immune responses [47].

In addition to the effects of hormones and danger signals, immune rhythms are regulated by intrinsic cellular clocks that have been demonstrated in peritoneal and splenic macrophages as well as peripheral Th cells and are capable of maintaining periodic changes in pro-inflammatory cytokine production for several days in vitro (Bollinger et al., under revision) [64]. Clock genes control up to $8 \%$ of the transcriptome in immune cells, amongst others, components involved in antigen presentation, phagocytosis and LPS, HSP and NFKB signalling (Bollinger et al., under revision) $[10,60,65]$. Accordingly, various other indices of immune 
function, like phagocytosis [59], activity of natural regulatory $\mathrm{T}$ cells as well as spontaneous and stimulated cell proliferation in peripheral blood, lymph nodes and spleen, have been revealed to display diurnal rhythms, also peaking during the rest period $[8,20,41]$. Interestingly, in the latter study, blood levels of GH and prolactin correlated positively with unstimulated IFN- $\gamma$ production and with the stimulated mitogenic response in rat lymph nodes suggesting an active contribution of these pro-inflammatory hormones to the rhythm in immune function [41]. On the other hand, low sympathetic activity (as assessed by tyrosine hydroxylase activity) seemed to contribute to the high spontaneous $\mathrm{T}$ cell proliferation in lymph nodes $[19,20]$.

Taken together, neuroendocrine rhythms with the prevalent release of pro-inflammatory hormones and a suppression of anti-inflammatory hormones particularly during the early SWS-rich portion of the rest period in combination with an accumulation of endogenous and exogenous danger signals across the active wake period and the intrinsic clock gene activity synergistically impact immune and nonimmune cells to boost immune activation during the rest period. This pro-inflammatory function of sleep can be beneficial. Thus, sleep after vaccination can enhance the subsequent adaptive immune response like an adjuvant (see below). On the other hand, the pro-inflammatory surge during sleep can also be detrimental as evidenced by peak mortality rates in mice when LPS is injected during the sleep period $(83 \%)$ in comparison with injection during the active period $(10 \%)$, a pattern that is similarly observed for mortality rates in septic patients $[56,100]$.

During the sleep phase, immune cells at early stages of differentiation peak in peripheral blood and lymph nodes

Immune cells migrate. New cells are constantly released from the bone marrow into the circulation. $\mathrm{T}$ and $\mathrm{B}$ cells circulate for up to years until they encounter their cognate antigen in secondary lymphatic tissues, whereas other cells, like macrophages, DC and neutrophils, extravasate to peripheral tissues already after a few hours or days. In humans, recirculating $\mathrm{T}$ cells, mainly naïve and central memory $\mathrm{T}$ cells, through a mechanism involving CD62L, leave the blood via high endothelial venules (HEV) to enter the lymph nodes and then return to the blood via efferent lymphatics and the thoracic duct [127]. In peripheral blood, these cells show a pronounced circadian rhythm with a peak during the early rest period. A closely comparable rhythm is observed for lymphocytes, T cells and Th cells in lymph nodes, indicating that there is a fast equilibrium between the blood and this lymphatic compartment $[10,34,40]$. In addition, there is evidence pointing to an accumulation of lymphocytes in lymph nodes during nocturnal sleep [29, 129].
In humans, rhythms of $\mathrm{T}$ cells in blood are coupled to the rhythm of cortisol such that the peak in cortisol in the beginning of the wake period precedes a decrease in blood $\mathrm{T}$ cell number by about $3 \mathrm{~h}$. This coupling presumably reflects the cortisol-mediated redirection of $\mathrm{T}$ cells to the sheltering bone marrow during the active period via enhanced expression of CXCR4 [26, 34] (Fig. 2). In fact, the corresponding ligand in bone marrow, i.e. CXCL12, is likewise rhythmically produced with a parallel peak during the active period. However, this rhythm seems to be mainly governed by clock genes and the SNS [86]. CXCR4 is not only expressed on mature $\mathrm{T}$ cells at early stages of differentiation, but also by hematopoietic stem cells that-like naïve and central memory $\mathrm{T}$ cells - show the highest numbers in peripheral blood in the beginning of the rest period in animals and humans [78]. The decrease in HPA and cortisol activity during the rest period releases $\mathrm{CXCR} 4^{+} \mathrm{T}$ cells from the bone marrow, presumably to enable their subsequent distribution to other sites of action, for example to the lymph nodes where they can initiate adaptive immune responses. Low levels of cortisol could likewise facilitate the extravasation of $\mathrm{T}$ cells from the blood to lymph nodes, as glucocorticoids are known to impair lymphocyte migration across HEV presumably via effects on the endothelium [26]. However, discrepant findings in animal studies suggest the presence of species-specific differences in the regulation of immune cell rhythms in lymph nodes [50]. In addition to nadir glucocorticoid levels, other factors like high levels of $\mathrm{GH}$ and low SNS activity could contribute to the accumulation of lymphocytes in lymph nodes during early sleep [57, 90, 104, 117].

Collectively, these findings provide strong evidence for the notion that processes of immune activation and proliferation involving pro-inflammatory signals, APC, naïve and central memory $\mathrm{T}$ cells in lymph nodes are timed to the resting period. The reason for this timing is not clear. However, inflammation, if present during waking, causes malaise, fatigue, immobility, pain and other aspects of sickness behaviour that are incompatible with the demands of mental and physical activity required for effectively coping with environmental challenges. Hence, confining it to sleep time seems reasonable [92]. In addition, immune activation, especially protein synthesis and cell proliferation, needs energy, and the endocrine changes during sleep allow for the allocation of energy-rich fuels like glucose from insulin-dependent tissues (e.g. muscle) to the immune system [58, 114]. Finally, inflammation leads to oxidative stress and cell injury that are efficiently counteracted by melatonin scavenging free radicals and by hematopoietic stem cells providing cellular supply. These may be just some reasons favouring the sleep period as suitable time for initiating adaptive immune responses and associated pro-inflammatory activity. Never- 


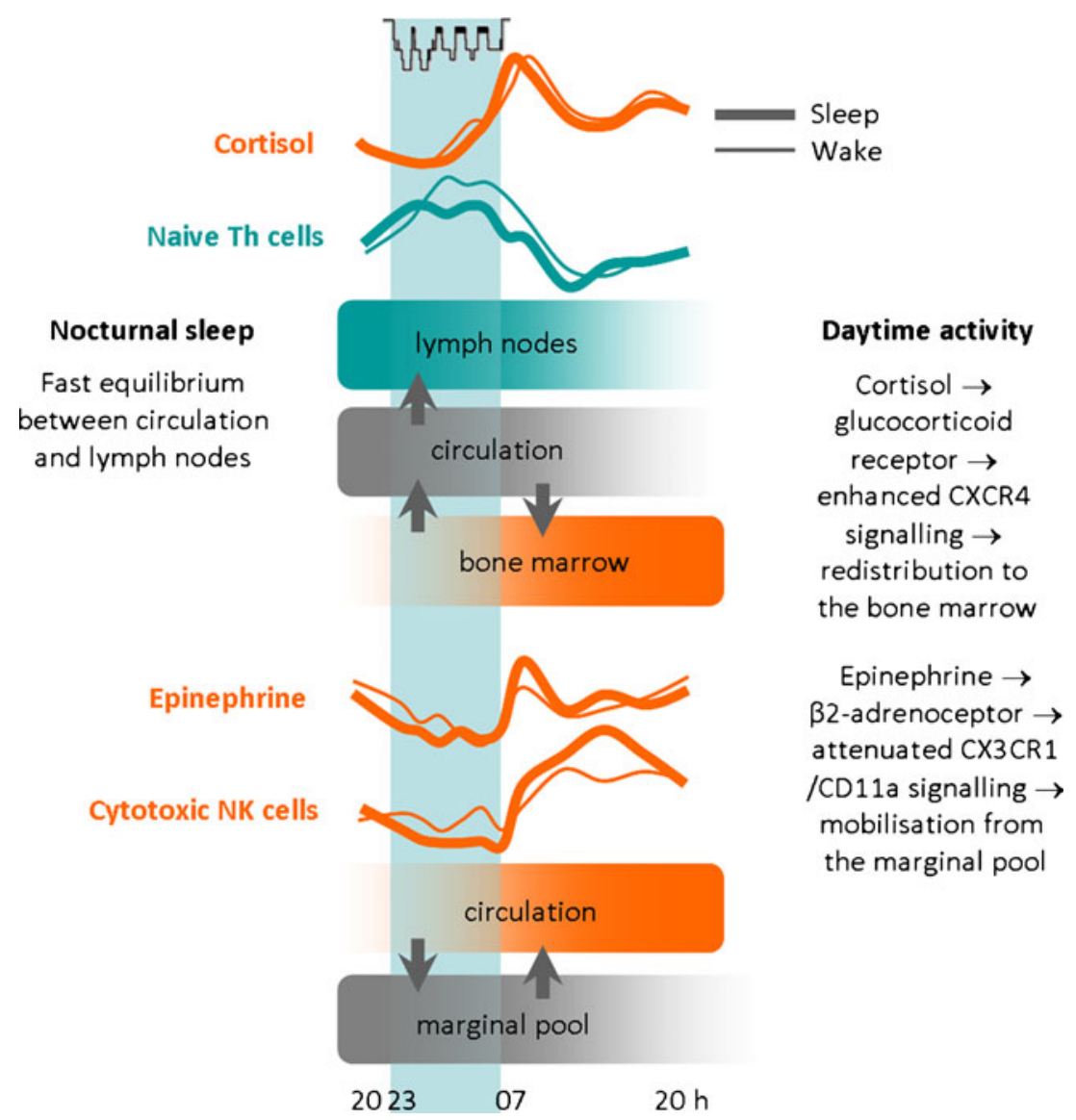

Fig. 2 Combined impact of sleep, the circadian rhythm and associated release of cortisol and epinephrine on rhythms and redistribution of leukocyte subsets. Sleep compared with nocturnal wakefulness enhances the homing of naïve $\mathrm{T}$ helper $(T h)$ cells to lymph nodes which leads to slightly reduced numbers of these cells circulating in blood during sleep. The mechanisms of this enhanced homing of cells during sleep are not understood. During daytime wakefulness, the circadian rise in cortisol induces an increase in CXCR4 expression on undifferentiated or less differentiated leukocytes, like naïve Th cells, which in turn enables the redistribution of

theless, pathogen encounter takes place mainly during the active period. So, why should the immune system wait for several hours before being activated? In the next section, we will outline that the wake period is associated with a completely different type of immune defence that acutely wards off any challenges in peripheral tissues and spleen, before the aforementioned slower, long-term processes of adaptive immunity develop in the lymph nodes.

Cytotoxic effector functions prevail in the wake period

Already during the late portion of nocturnal sleep in humans, HPA activity increases in order to prepare the organism for daytime activity. Upon awakening, there is a further rise in the stress hormones, i.e. of adrenocortical cortisol, of epinephrine released from the adrenal medulla and of norepinephrine that is released from sympathetic these cells to the bone marrow. On the other hand, epinephrine controls the rhythm of highly differentiated leukocytes, like cytotoxic natural killer $(N K)$ cells, acting as effector cells. During daytime wakefulness, the enhanced activation of $\beta 2$-adrenoceptors by epinephrine attenuates CX3CR1/CD11a signalling, which leads to an enhanced mobilisation of theses cells from the marginal pool during daytime. Reduced epinephrine levels during sleep (compared to nocturnal wakefulness) allow the margination of these cells, which results in lower cell numbers in peripheral blood. Modified from Lange and Born [71]

nerve endings and spills over into the circulation [36, 128]. These stress hormones have a strong anti-inflammatory potential and presumably shut down the pro-inflammatory response evoked during nocturnal sleep [39, 73, 99]. Indeed also the major anti-inflammatory cytokine IL-10 is produced by stimulated monocytes in a similar periodic fashion, reaching peak levels in the morning hours of the wake period [73].

In addition to this counter-regulatory function of the stress systems, the SNS mobilises subsets of leukocytes with cytotoxic effector potential. In 1997, Suzuki et al. described a group of phylogenetically more primitive immune cells that have been termed 'stress leukocytes'. These cells exhibit high expression of $\beta$-adrenoceptors and, in humans, increase in peripheral blood during daytime activity [116]. The cell group encompasses terminally differentiated CD45RA ${ }^{+}$effector CTL, cytotoxic NK cells, 
NKT cells, NKT like cells and $\gamma \delta \mathrm{T}$ cells which are all highly differentiated cells with a long replicative history and short telomere length $[16,34,35]$. Their cytotoxicity derives from toxic substances like granzyme and perforin in preformed vesicles, on preformed IFN- $\gamma$ and/or on the expression of apoptosis inducing Fas ligand, so that they are able to rapidly kill infected or transformed, cancerous cells [16]. Stress leukocytes reside within the marginal pool, i.e. they are attached to the endothelium of postcapillary venules via CX3CR1/CD11a signalling and are mobilised within seconds upon stimulation of their $\beta 2$ adrenoceptors by epinephrine [3, 35] (Fig. 2). In contrast to lymphocytes at early stages of differentiation, stress leukocytes do not recirculate, have a shorter life span, need no co-stimulation (and accordingly lack the respective co-stimulatory receptors like CD27 and CD28) and show minor proliferative responses to mitogens or antigens, features that well explain their immediate effector potential and possibly also their reduced sensitivity towards slower acting hormones like glucocorticoids [16, 34].

Neutrophils, pro-inflammatory monocytes and DC are likewise stress leukocytes that are mobilised into the circulation by the SNS. However, available evidence points to an additional involvement of norepinephrine acting on $\alpha$-adrenoceptors $[35,115,125]$. 'Adrenergic leukocytosis' is interpreted as an enhanced immunosurveillance in order to rapidly respond to injury and concurrent infectious challenge, as stress leukocytes display a high tissue migratory potential and are efficiently redistributed from the circulation to the site of action, e.g. to the skin, concomitant with a drop in their circulating numbers $[16,27]$. Consistent with this, experimental short-term $(2-3 \mathrm{~h})$ restraint stress in comparison to a no-stress control facilitated the accumulation of macrophages in a surgically implanted sponge used as an experimental model of the early immune cell recruitment in the context of wounding [123]. The same type of stressor also enhanced the accumulation of effector T cells upon antigen re-challenge in the skin in an experimentally induced delayed type hypersensitivity reaction [124]. In addition, the adjuvant-like action of acute (restraint) stress during first-time antigen exposure seems to comprise a facilitated migration of macrophages and DC after antigen uptake to draining lymph nodes via afferent lymphatics, a process involving $\alpha$-adrenoceptors and norepinephrine signalling $[80,99,124]$. Thus, acute stress indirectly supports $\mathrm{T}$ cell priming via $\mathrm{DC}$ rather than via direct effects on $\mathrm{T}$ cells, the number of which in draining lymph nodes is increased not until $24 \mathrm{~h}$ after stress [99, 124].

Interestingly, the 'mature' type of DC in lymph nodes that is capable of $\mathrm{T}$ cell activation loses $\alpha$-adrenoceptor expression [80], and the remaining $\beta$-adrenoceptors are known to mediate suppressive effects of catecholamines on pro-inflammatory cytokine production [39, 99]. It is therefore tempting to speculate that at this time, i.e. several hours after stress and antigen encounter during the wake phase, the beneficial effects of pro-inflammatory sleep with low levels of endogenous catecholamines will kick in to support subsequent $\mathrm{T}$ cell activation by mature $\mathrm{DC}$ in lymph nodes.

\section{Sleep impacts immune function}

\section{Methodological remarks}

It is basically difficult to dissect the influence of sleep per se from that of the circadian rhythm and associated changes in behaviour. The marked sleep-wake rhythm which we referred to in the previous section is jointly controlled by both the circadian system and sleep, but also by confounding influences like body posture, physical activity, feeding and fasting, lighting and ambient temperature. Experimental procedures that optimally disentangle these influences are highly elaborate and require frequent blood sampling for at least $24 \mathrm{~h}$ under conditions of constant routine with bed rest, dim light, constant ambient temperature and periods of food intake and sleep either equally distributed across the $24 \mathrm{~h}$ (e.g. every $1.5 \mathrm{~h}$ ) or scheduled to specific time intervals. Indeed, there are only a few studies in humans investigating the effects of sleep on immune functions that fulfilled some of the essential requirements of constant routine protocols, and most of these studies compared the effects of sleep during a regular sleep-wake cycle with those of a 24-h period of continuous wakefulness. Figure 2 summarises the effects of sleep on rhythms of cortisol, epinephrine, naïve Th cells and cytotoxic NK cells observed in these studies. They show that for given immune parameters in healthy humans, sleep can exert enhancing, suppressing or no effects depending on the time of the blood draw. For most parameters, the 24-h mean (mesor) remained unchanged between the conditions of regular sleep and 24-h wakefulness, suggesting a robust homeostatic control by circadian mechanisms that is not persistently challenged by a single night of sleep loss. Other studies employed partial sleep deprivation and sleep restriction protocols with very different time schedules (e.g. sleep from 11 p.m. to 3 a.m., from 1 a.m. to 5 a.m. or from 3 a.m. to 7 a.m.). However, these approaches revealed an even more complex picture of interactions between sleep and circadian effect.

Moreover, many studies combined partial or total sleep deprivation with only a single blood sampling once in the 
morning after the nocturnal intervention. However, because the effect of sleep vs. sleep deprivation clearly depends on the time of the assessment, a single blood draw usually does not provide any conclusive data. Frequent blood sampling is also required in light of the fact that hormones mediating the effects of sleep on immune parameters exert these effects with very different kinetics. For example, immune cell mobilising effects of catecholamines occur within minutes whereas the effects of cortisol on immune cell migration occur more gradual and take $2-3 \mathrm{~h}$ to develop [34].

Considering the profound changes in cell composition over $24 \mathrm{~h}$, the basic question also arises whether changes in cell function (e.g. cytokine production, T cell proliferation, NK cell activity) or cell characteristics (e.g. changes in the expression of adhesion molecules) that are observed during a 24-h period indeed reflect respective alterations in single cells or are merely secondary to the fact that the proportion of relevant cell subsets circulating in blood changed. Therefore, a measurement of the immune parameter of interest on a per cell basis (e.g. by means of flow cytometry) is advantageous. Despite these methodological pitfalls, the available studies have accumulated quite consistent evidence that sleep indeed essentially contributes to the regulation of adaptive immunity.

Acute effects of regular sleep compared to $24 \mathrm{~h}$ of continuous wakefulness

Here we concentrate on studies in humans which compared the effects of a regular sleep-wake cycle, where sleep occurs during the rest period, with a condition of $24 \mathrm{~h}$ of continuous quiet wakefulness, and which applied repeated blood drawings. As outlined above, this approach appears to be most advantageous in order to disentangle the effects of sleep from those of the circadian system. The main outcomes from these studies are summarised in Table 1. The focus is on studies in humans, because unlike animals, humans voluntarily undergo experimental procedures like sleep deprivation which limits the confounding effects of stress. In fact, blood levels of cortisol and catecholamines during a nocturnal vigil in humans are typically only slightly elevated compared with the levels during nocturnal sleep, and these levels are far from those characterising
Table 1 Effects of nocturnal sleep compared with 24$\mathrm{h}$ wakefulness on immune parameters

For cytokine activity, the leukocyte subset analysed and whether cytokine activity was measured after stimulation of cells or not (unstimulated) is indicated in brackets

$W B C$ white blood cells, $N K$ cells natural killer cells, Th cells $\mathrm{T}$ helper cells, CTL cytotoxic $\mathrm{T}$ lymphocytes, $p D C$ plasmacytoid dendritic cells, pre-mDC pre-myeloid dendritic cells, $n T_{\text {reg }}$ natural regulatory $\mathrm{T}$ cells, IL interleukin, $T N F$ tumour necrosis factor, IFN interferon

${ }^{\mathrm{a}}$ Effect reversed during late sleep or subsequent daytime

${ }^{b}$ No change if related to the numbers of circulating monocytes

\begin{tabular}{|c|c|c|}
\hline Immune parameter & Effect of sleep & Reference \\
\hline \multicolumn{3}{|l|}{ Cell counts } \\
\hline $\begin{array}{l}\text { WBC, total monocytes, CD } 14^{\mathrm{dim}} \mathrm{CD} 16^{+} \text {monocytes, total } \\
\text { lymphocytes }{ }^{\mathrm{a}} \text {, total NK cells }{ }^{\mathrm{a}}, \mathrm{CD} 16^{+} \mathrm{CD} 56^{\mathrm{dim}} \mathrm{NK} \text { cells, } \\
\text { total B cells, total T cells, Th cells }{ }^{\mathrm{a}}, \mathrm{CTL}^{\mathrm{a}} \text {, activated } \\
\text { T cells }{ }^{\mathrm{a}}, \mathrm{pDC}\end{array}$ & $\downarrow$ & {$[13,33]$} \\
\hline $\begin{array}{l}\text { Pre-mDC, total monocytes, } \mathrm{CD} 14^{+} \mathrm{CD} 16^{-} \text {monocytes, } \\
\mathrm{CD} 16^{-} \mathrm{CD} 56^{\text {bright }} \mathrm{NK} \text { cells, } \mathrm{nT}_{\text {reg }}\end{array}$ & $=$ & {$[8,33]$} \\
\hline \multicolumn{3}{|l|}{ Cytokine activity } \\
\hline $\begin{array}{l}\text { IL-2 (stimulated whole blood), IFN- } \gamma / \mathrm{IL}-4 \text { ratio (stimulated } \\
\text { Th cells) }{ }^{\mathrm{a}} \text {, IL-7 (unstimulated whole blood), TNF- } \alpha \\
\text { (stimulated monocytes), } \\
\text { IL-12 (stimulated monocytes), IL-12 (stimulated pre-mDC) }\end{array}$ & $\uparrow$ & {$[1,13,31,33,73,74]$} \\
\hline $\begin{array}{l}\text { IL-10 (stimulated monocytes), IL-4 (stimulated Th cells) }{ }^{\mathrm{a}} \text {, IFN- } \gamma \\
\text { (stimulated CTL), TNF- } \alpha \text { (stimulated CTL), TNF- } \alpha \\
\text { (stimulated whole blood) }{ }^{\mathrm{b}}, \text { IL-1 } \beta \text { (stimulated whole blood) }{ }^{\mathrm{b}}\end{array}$ & $\downarrow$ & {$[31,73]$} \\
\hline $\begin{array}{l}\text { IL-15 (membrane-bound on monocytes, stimulated } \\
\text { monocytes), } \\
\text { IL-2 (stimulated Th cells), IL-6 (stimulated monocytes), IL-6 } \\
\text { (unstimulated whole blood), IFN- } \alpha \text { (stimulated whole blood), } \\
\text { IFN- } \alpha \text { (stimulated whole blood, divided by numbers of pDC) }\end{array}$ & $=$ & {$[1,8,13,31-33]$} \\
\hline \multicolumn{3}{|l|}{ Cytokine receptors } \\
\hline Soluble IL-6 receptor & $\uparrow$ & {$[32]$} \\
\hline $\begin{array}{l}\text { Soluble IL- } 2 \text { receptor, soluble TNF- } \alpha \text { receptors, } \\
\text { membrane-bound IL- } 6 \text { receptor, soluble gp } 130\end{array}$ & $=$ & {$[31,32,54]$} \\
\hline \multicolumn{3}{|l|}{ Other parameters } \\
\hline Th cell proliferation & $\uparrow$ & {$[8]$} \\
\hline $\mathrm{nT}_{\text {reg }}$ activity & $\uparrow$ & {$[8]$} \\
\hline NK cell activity & $\downarrow$ & {$[81]$} \\
\hline Complement system & $\uparrow$ & {$[95]$} \\
\hline Response to vaccination & $\uparrow$ & {$[72,75]$} \\
\hline
\end{tabular}


stress [13, 31, 33, 72, 73, 75, 81]. Accordingly, considering that keeping a human awake for a single night (or less) does not represent a major stress, we prefer in this context not to speak of 'sleep deprivation' but rather of 'continuous wakefulness', where the stress levels during the night and during daytime are entirely comparable. Of course, longer periods of wakefulness do represent a condition of predominant stress, to which the organism responds in a manner very similar as to other stressors. However, such conditions are not suitable to investigate the functions of sleep, but rather allow for the investigation of the effects specific to a certain stressor. We will shortly discuss these effects of stress induced by prolonged sleep deprivation on immunity separately in the end of this chapter, as they nevertheless bear some further implications for the role of sleep in immunity.

As outlined above, the numbers of immune cells in peripheral blood show a prominent sleep-wake rhythm over the 24-h period, with peaks and nadirs occurring at different times depending on the cell subset of interest. Generally, these rhythms are not abrogated under conditions of 24-h continuous wakefulness. Rather, sleep influences their amplitude and can shift their peak forward or backward in time. For most of the lymphocyte subsets studied, sleep, in comparison with continuous wakefulness, was shown to reduce cell counts in blood during the night whereas this decrease is compensated by increased cell numbers during subsequent daytime [13]. This is true for Th cells, CTL, activated T cells as well as NK cells. In contrast, B cell numbers did not show a compensating enhancement during the following day. In the same study [13], monocyte counts were also depressed during sleep compared with nocturnal wakefulness. However, a more recent study [33] showed that sleep reduced mainly the circulating number of rare $\mathrm{CD} 14^{\mathrm{dim}} \mathrm{CD} 16^{+}$monocytes, which compared with $\mathrm{CD} 14^{+} \mathrm{CD} 16^{-}$monocytes have a greater capability to invade tissues under noninflammed conditions [48]. $\mathrm{CD} 14^{+} \mathrm{CD} 16^{-}$monocyte counts remained unchanged during nocturnal wakefulness. Similarly, numbers of $\mathrm{CD} 16^{+} \mathrm{CD} 56^{\mathrm{dim}} \mathrm{NK}$ cells, which are also termed cytotoxic NK cells and have immediate effector functions, were suppressed during sleep, while the small fraction of immuno-regulatory $\mathrm{CD} 16^{-} \mathrm{CD} 56^{\text {bright }} \mathrm{NK}$ cells, which show low natural cytotoxicity [25], remained unaffected by sleep [33]. The latter study also identified two subsets of DC precursors to be differentially sensitive to the effects of sleep. The numbers of pDC, which produce large amounts of IFN$\alpha$ in response to viral challenges and are capable of directly regulating T cell functions [76], were reduced during sleep, whereas cell counts of total pre-myeloid DC (pre-mDC), which are characterised mainly by IL-12 production, did not change although, as discussed below, sleep strongly enhanced the proportion of IL-12-producing pre-mDC [33].
Collectively, these findings show that sleep selectively modulates some leukocyte subsets but leaves unaffected others. Sleep specifically reducing certain subpopulations of monocytes, NK cells and DC precursors is consistent with the view of a coordinate control that is exerted by this brain state on immune functions. Importantly, the reductions in leukocyte numbers observed during regular sleep in no case should be used to infer a general suppression of immune functions. Rather, such decreases most likely represent a redistribution of the cells to different extravascular compartments or an enhanced margination to the endothelium of postcapillary venules. For example, naïve $\mathrm{T}$ cells which express high levels of CD62L, a receptor needed for homing to secondary lymphoid organs [126], appear to be redistributed to lymph nodes during sleep [74], whereas the reduction of cytotoxic NK cell numbers likely reflects a margination of these cells to the vessel walls due to a drop of epinephrine levels [35].

Whereas changes in cell counts measured in blood do not allow for unequivocal conclusions as to the physiological implications these changes may have, many studies aimed at directly assessing functional aspects of immune cells, such as cytokine production and cell proliferation. There is consistent evidence that sleep, in comparison with nocturnal wakefulness, favours the production of proinflammatory and Th1 cytokines. Thus, sleep strongly enhanced the production of IL-12 by pre-mDC which are precursor cells most closely related to mature APC [33] (Fig. 3a). IL-12 is a key cytokine for the induction of Th1type adaptive immune responses. Production of IL-12 by monocytes was likewise increased by sleep, whereas production of the anti-inflammatory cytokine IL-10 by monocytes was concurrently reduced [73]. Moreover, during early sleep, the balance between Th1 and Th2 cytokines was revealed to be shifted towards a dominance of Th1 cytokine production as evidenced by an increased ratio in the IFN- $\gamma / \mathrm{IL}-4$ production by Th cells. Interestingly, the shift is replaced by a reduced IFN- $\gamma / \mathrm{IL}-4$ ratio, i.e. a predominance of Th2 cytokine production during late sleep [31]. This pattern suggests that the pro-inflammatory action of sleep concentrates during the early portion of nocturnal sleep when SWS is dominant and that counter-regulatory processes develop already during the late portion of sleep when rapid eye movement sleep prevails. The latter study [31] in addition revealed a reducing effect of sleep on IFN$\gamma$ as well as TNF- $\alpha$ production by CTL, suggesting that sleep does not non-specifically support production of proinflammatory cytokines in all cells. However, this reducing effect of sleep could also reflect that due to a sleepassociated drop in epinephrine levels cytokine-producing effector CTL marginate to the vessel walls (and are then no more available for blood sampling and flow cytometric cytokine assessment). 


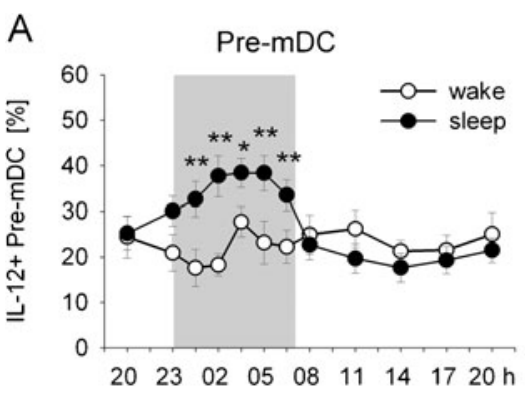

Fig. 3 Sleep compared to nocturnal wakefulness selectively enhances the production of interleukin $(I L)-12$ by pre-myeloid dendritic cells (pre- $m D C$ ) which is important for the initiation of adaptive immune responses, whereas it does not influence the levels of interferon (IFN)$\alpha$ that is released as an early response of the innate immune system upon viral infection. a The percentage of pre-mDC producing IL-12 measured after lipopolysaccharide stimulation of peripheral blood samples from healthy young men during a regular sleep-wake cycle

Another prominent pro-inflammatory cytokine is IL-6. Although overall findings regarding this cytokine remain conflicting, no consistent effects of sleep were found on the production of IL- 6 by monocytes or absolute plasma concentrations $[13,32,53]$, which at first glance may be surprising. However, IL-6 is mainly involved in regulating the early innate, rather than the adaptive, immune response to bacterial infection. Thus, the enhancing effects of sleep sparing this cytokine would be well in line with the view that sleep preferentially supports the production of cytokines that are directly involved in mounting adaptive immune responses in lymphoid organs. In consonance with this view, another study [33] likewise did not reveal any effect of sleep on absolute plasma levels or the herpes simplex virus 1-stimulated production of IFN- $\alpha$, an important pro-inflammatory regulator of the innate response to viral infection (Fig. 3b). On the other hand, serum concentrations of IL-7, which supports $\mathrm{T}$ cell growth and the differentiation of memory $\mathrm{T}$ cells, was found to be distinctly enhanced during sleep, in particular during the late period of the night [1]. However, membrane-bound IL15 sharing some of the functions of IL-7 remained uninfluenced in this study, again underlining that the effects of sleep on cytokine activity are highly selective.

Amongst the studies focussing on the effects of sleep on cytokine activity, there are some seemingly discrepant findings. However, these are probably due to differences in the assessment of cytokine activity. For example, IL-1 $\beta$ and TNF- $\alpha$ levels when measured after stimulation of whole blood samples are decreased by nocturnal sleep [13]. Yet, this effect completely vanishes when the changes in IL- $1 \beta$ and TNF- $\alpha$ activity are related to the number of monocytes producing these cytokines, as the number of these cells circulating in the blood are likewise reduced by sleep. Such observations underline the importance to measure immune cell functions, like the production of

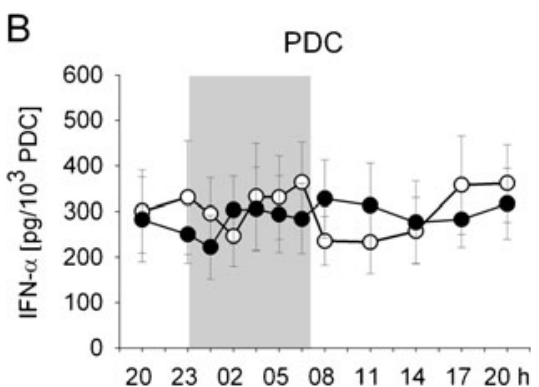

(black circle) and during $24 \mathrm{~h}$ of continuous wakefulness (white circle). Analyses were performed by flow cytometry. b IFN- $\alpha$ production of plasmacytoid DC $(p D C)$. Values indicate IFN- $\alpha$ concentrations measured by ELISA in whole blood samples after herpes simplex virus 1 stimulation, divided by the number of pDC. Means $( \pm \mathrm{SEM})$ are shown. Shaded area indicates bed time. ${ }^{*} p<.01$, $* p<.05$ for pairwise comparison between conditions at single time points. Modified from Dimitrov et al. [33]

cytokines, in blood samples on a per cell basis. Indeed, identifying the percentage of monocytes producing TNF- $\alpha$ showed that sleep even enhanced the production of this cytokine [74], whereas the percentage of TNF- $\alpha$ producing CTL was decreased [31]. Differences in the procedure of cytokine measurement probably account also for some of the conflicting data concerning IL-2, which critically supports the development, proliferation and differentiation of T cells. Whereas IL-2 activity was found to be enhanced by sleep when the cytokine was determined after mitogen stimulation of whole blood samples (for example [13]), this finding was not replicated by others determining IL-2 production specifically for Th cells $[8,31]$. The use of whole blood vs. isolated cells, assessment of stimulated vs. unstimulated cytokine production, relation to the numbers of cytokine-producing cells vs. absolute cytokine levels, the type of antigen used for stimulation and even the use of different anticoagulants [95] can be all factors producing discrepant results. Nevertheless, despite the variety in the procedures used for assessing cytokine activity, the overall picture arising from these studies speaks for an enhancing influence of sleep preferentially on pro-inflammatory cytokine production specifically by immune cells contributing to the development of adaptive immune responses.

Analyses of receptors mediating cytokine effects provide further information as to the role of sleep in the regulation of immune function, although so far only a few studies examined cytokine receptors in this context. Membranebound and soluble forms of cytokine receptors exist which can mediate quite different type of action even of the same cytokine. Compared with continuous wakefulness, sleep strongly enhanced the concentrations of the soluble IL-6 receptor, whereas the membrane-bound IL-6 receptor remained uninfluenced [32]. It was concluded that sleep serves to enhance IL-6 trans-signalling, that is, effects on cells which do not express IL-6 receptors on their 
membrane but are able to receive IL- 6 signals through the involvement of the soluble form of the receptor acting in concert with membrane-bound gp130 [61]. Whereas the expression of membrane-bound IL-6 receptors mainly concentrates on various immune cell populations, by trans-signalling via its soluble receptor, IL-6 affects a great variety of other cells and systems including the brain. Generally, by enhancing trans-signalling, sleep widens the profile of IL- 6 actions enabling a more integrated action of the cytokine on the brain and peripheral organ systems. Of relevance here, in this way, sleep is expected to increase a feedback control the cytokine exerts over brain structures promoting sleep and particularly SWS [2, 106]. Other studies explored the effects of sleep on soluble forms of TNF- $\alpha$ and IL-2 receptors [31, 54]. However, concentrations of both receptors were not found to be altered by nocturnal sleep.

The effects of sleep were examined also on other functional aspects of immunity, besides cytokine activity. Thus, Matsumoto et al. [81] investigated sleep effects on NK cell activity in a standard assay of subcultured target cells. NK cell activity was transiently reduced during sleep as compared to nocturnal wakefulness, although the method employed did not allow to discriminate whether this decrease was merely a consequence of reduced numbers of NK cells in the blood, which were not assessed in this study, but were shown to be reduced during sleep by others [13]. A recent study of the components of the complement system showed that sleep increases activation of the complement system as reflected by enhanced plasma levels of the anaphylotoxin C3a [95]. Given that anaphylotoxins like C3a not only exert pro-inflammatory actions but also contribute to APC regulation, for example by supporting the production of IL-12, this finding well agrees with the view of a promoting influence of sleep on APC-T cell interactions. The influence of regular sleep on the activity of natural regulatory $\mathrm{CD} 4^{+} \mathrm{CD} 25^{+} \mathrm{T}$ cells $\left(\mathrm{nT}_{\text {reg }}\right)$ was assessed measuring the suppressing influence of these cells on the proliferation of $\mathrm{CD} 4^{+} \mathrm{CD} 25^{-} \mathrm{T}$ cells [8]. The main function of $\mathrm{nT}_{\text {reg }}$ is to dampen excessive immune responses. Whereas the number of circulating $\mathrm{nT}_{\text {reg }}$ was not influenced by sleep, their activity turned out to be strongly reliant on normal nocturnal sleep, with virtually no suppressive activity in the condition of nocturnal wakefulness. Interestingly, the proliferation of $\mathrm{CD} 4^{+} \mathrm{CD} 25^{-} \mathrm{T}$ cells was likewise enhanced by sleep, leading the authors to conclude that sleep might be essential for a balanced homeostatic regulation of the immune system. Indeed, the prevalent pro-inflammatory activity accompanying early SWS-rich sleep might be kept in check by sleep concurrently promoting activity of $\mathrm{nT}_{\text {reg }}$ cells.

In sum, research during the past years has accumulated evidence that sleep affects a wide variety of immune functions, including the numbers of specific leukocyte subsets in circulating blood, the cell-specific production of cytokines and further immune cell functions. The effect of sleep is selective influencing some components of the immune system but not others. Sleep appears to preferentially promote the pro-inflammatory cytokine production important for the mounting of adaptive immune responses, and this action might primarily affect less differentiated immune cells, although the cell subset-specific production of cytokines needs to be further explored in this context. The pro-inflammatory actions of sleep mainly originate from the early SWS-rich part of nocturnal sleep. However, excessive pro-inflammatory activity becomes counterregulated in the course of sleep as indicated, for example, by the concurrent upregulation of $\mathrm{nT}_{\text {reg }}$ activity and a predominance of Th2 activity during late sleep. The enhancement of IL-12 production by important precursors of APC, together with a shift towards Th1 cytokines and a reduction of blood lymphocyte counts possibly reflecting a redistribution of these cells to secondary lymphoid organs, point to a supportive role of sleep in the initiation of an adaptive immune response, eventually leading to immunological memory.

Sleep enhances the formation of immunological memory

How does sleep affect immunity during a genuinely ongoing immune response? There are quite a few studies that investigated the effects of sleep on the response to vaccinations used as an experimental model of infection. Intriguingly, these studies consistently demonstrate that sleep enhances the adaptive immune response against the invading antigen. Compared with subjects who stayed awake during the night after a single vaccination against hepatitis A in the morning before, subjects who regularly slept on this first night after vaccination, 4 weeks later, displayed a twofold increase in antigen-specific antibody titres [72]. This study was the first to show in humans that a single night of normal sleep after vaccination strengthens the evolvement of a natural immune response against an invading antigen, to a clinically relevant extent. Subsequent experiments confirmed these effects for repeated inoculations with both hepatitis A and B antigens and showed that the immune-boosting effect of nocturnal sleep was also reflected by a doubling of the number of circulating antigen-specific $\mathrm{Th}$ cells that drive the production of hepatitis A and B-specific antibodies [75] (Fig. 4a). The proportion of pro-inflammatory and Th1 cytokine (IL-2, IFN- $\gamma$, TNF- $\alpha$ ) producing T cells was also profoundly reinforced by sleep. Importantly, these immuno-enhancing effects of sleep were still present at a 1-year follow-up, indicating that sleep in enhancing the initial formation of an adaptive immune response also supports the long-term 
A

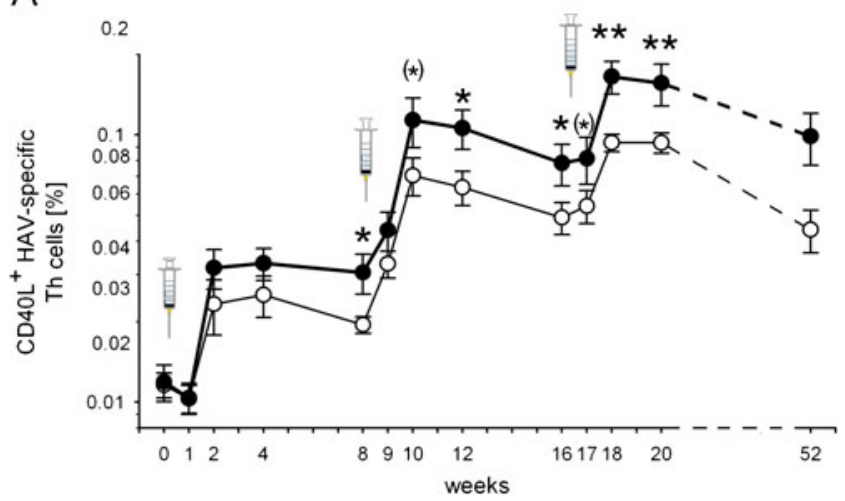

B
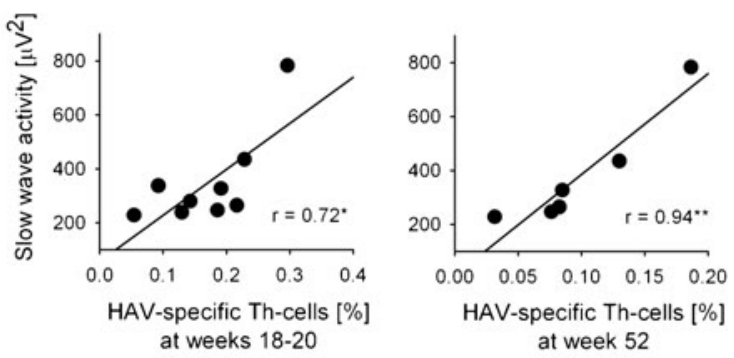

C

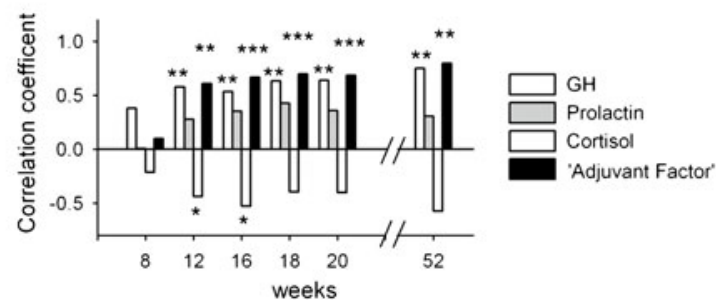

Fig. 4 Sleep enhances the hepatitis A virus $(H A V)$-specific $\mathrm{T}$ helper (Th) cell response to vaccination which is strongly predicted by EEG slow wave activity during slow wave sleep (SWS) and associated release of immune regulatory hormones during early SWS-rich sleep. a Emergence of $\mathrm{CD} 40 \mathrm{~L}^{+} \mathrm{HAV}$-specific Th cells (percentage of total Th cells) after HAV vaccination (three shots at weeks 0,8 and $16-$ vertical syringes) in two groups of subjects who either slept (black circle, thick line) or stayed awake (white circle, thin line) in the night following inoculations. $y$-axis $\log$ transformed. Means \pm SEM are indicated. $n=12-27$ for both groups. $\left.{ }^{*} p<0.01,{ }^{*} p<0.05,{ }^{*}\right) p<0.1$ for comparisons between sleep and wake conditions. $\mathbf{b}$ Scatter plots of the correlations between slow wave activity (averaged across the three post-inoculation nights) and the frequency of CD40L $\mathrm{L}^{+} \mathrm{HAV}$-specific Th cells (percentage of total Th cells) at weeks 18-20 (left panel) and week 52 (right panel). c Correlation coefficients between average GH, prolactin and cortisol concentrations during the early, SWS-rich part (0:30-2:00 a.m.) of post-inoculation nights and frequency of HAVspecific Th cells at weeks 8,12, 16, 18 and 20 and 1 year after HAV vaccination. (Analyses performed across sleep and wake groups.) Note the most robust correlations for an 'Adjuvant Factor' describing the synergistic action of the three hormones of interest by the formula $\mathrm{GH} \times$ prolactin/cortisol. ${ }^{* * *} p<0.001,{ }^{* *} p<0.01,{ }^{*} p<0.05$. Modified from Lange et al. [75]

maintenance of the antigenic memory, a function hallmarking the immune system.
The results of these vaccination experiments in healthy humans basically concur with the findings of early experiments in animals demonstrating the deleterious effect of sleep deprivation on the immune response to experimental viral infection [14]. Mice immunised with influenza virus failed to effectively clear the virus in response to a second challenge if they were sleep-deprived for $7 \mathrm{~h}$ immediately after the second challenge. However, others failed to replicate this finding or even found supportive effects of sleep deprivation [96, 97, 118]. These discrepant results might be related to the fact that so far all studies in animals investigated the effects of sleep on a secondary immune response, i.e. the recall of an antigenic memory formed at a previous primary response. This feature also prevents a direct comparison with the studies in healthy humans, discussed above, that concentrated on the effects of sleep on the primary response to infection, mediating the firsttime formation of the antigenic memory.

Altogether, the effects as described in the previous sections can be integrated in a model (as summarised in Fig. 1) attributing a main role of sleep to the formation and maintenance of immunological memory. After foreign antigenic particles invade into the organism, professional APC residing in the tissue incorporate the antigen and process it while they migrate to secondary lymphoid organs. Here, these cells present fragments of the antigen to naïve $\mathrm{T}$ cells, which are only activated if they express the specific receptor for the presented antigen. The release of IL-12 by the APC is essential for the activation of Th cells and their subsequent differentiation into Th1 cells. Sleep probably essentially strengthens this interaction between APC and T cells (forming the 'immunological synapse') by enhancing the production of IL-12 by APC, as sleep in fact was shown to enhance IL-12 production in the most important precursors of mature professional APC that circulate in blood, i.e. monocytes and pre-mDC $[33,73]$. Mature APC themselves do not circulate which hampers the direct assessment of their cytokine production during sleep. The adjuvant-like effect of sleep on the formation of adaptive $\mathrm{T}$ cell responses might be additionally strengthened by IL- 2 which, acting in a feed-forward manner, is a signal most important for $\mathrm{T}$ cell growth, proliferation and differentiation. Sleep can produce a distinct increase in the production of IL-2 $[13,60]$. The sleep-induced promotion of Th cell proliferation [8] and the shift of the Th1/Th2 balance towards Th1 cytokines during early SWS-rich sleep [31] likely represent further components of the immunoenhancing influence of sleep after vaccination. Effects similar in direction are expected by increases in $\mathrm{C} 3 \mathrm{a}$ produced by sleep [95], which exerts supportive influences on APC-T cell interactions, the production of IL-12 and the differentiation of Th cells towards a type 1 phenotype [112]. The view of a specific role of sleep in supporting 
APC-T cell interactions in lymphatic tissues is also consistent with the acute reduction in blood $\mathrm{T}$ cell numbers during sleep $[13,75]$ that likely reflects the enhanced migration of naïve and central memory $\mathrm{T}$ cells to lymph nodes, thereby promoting the encounter of these cells with professional APC. Finally, the enhancing effect of sleep on concentrations of IL-7 improving the survival of the T cell memory pool [1] could contribute to the persistence of the effects of sleep on the response to vaccination, and thus to the maintenance of the antigenic memory.

$\mathrm{GH}$ and prolactin were identified as important endocrine factors mediating the effects of sleep on the response to vaccination [75]. Release of these hormones is distinctly enhanced during sleep, especially during periods of SWS $[107,119]$, whereas secretory activity of the HPA axis is suppressed during early SWS [6, 12]. The sleep-induced release of $\mathrm{GH}$ and prolactin during the early night after vaccination together with the simultaneously reduced cortisol levels during this period was revealed to be highly correlated to the frequency of antigen-specific Th cells after vaccination [75] (Fig. 4c). GH and prolactin are wellknown to enhance the proliferation and differentiation of $\mathrm{T}$ cells as well as to promote type 1 cytokine activity [22, 23, $46,85]$. Also, both hormones act as adjuvants when given shortly after vaccination [105, 111]. Given that GH and prolactin are mainly released during SWS, this sleep stage seems to represent the major origin of the boosting effects of sleep on immune defence. In fact, the percentage of antigen-specific Th cells measured 1 year after vaccination against hepatitis A was highly correlated, with coefficients of $r>0.9$ with EEG slow wave activity, i.e. an indicator of the depth of SWS, measured on nights after vaccination [75] (Fig. 4b). These findings converge to the view that SWS prevalent during early nocturnal sleep induces an endocrine milieu which strongly supports the initiation of an adaptive immune response, laying the foundation for long-lasting immunological memory. It is worth mentioning here that sleep and particularly SWS have been likewise identified as the most important factors that support the formation of long-term memories in the neurobehavioural system [30], i.e. an entirely different domain. With this in mind, it is tempting to propose that the formation of longterm memories, as the basis for the organism's strategic adaptation to different kinds of environmental stressors (i.e. behavioural, immunological), represents a general function of sleep.

\section{Effects of prolonged sleep curtailment}

Unlike short periods of sleep deprivation for a single night or less, prolonged periods of sleep loss or sleep restriction for several days represent a condition of profound stress that can be used to analyse the detrimental changes in health and immune function that occur under conditions of chronic sleep curtailment, a condition prevalent also in modern society [11]. Different experimental designs were used to investigate the effects of prolonged sleep deprivation, with total sleep deprivation or restricted sleep for intervals between 4 and 10 days. The majority of these studies show that prolonged sleep curtailment leads to a general enhancement of markers for inflammatory activity. For example, Shearer et al. [102] reported that 4 days of continuous wakefulness result in an increase in plasma concentrations of IL- 6 and the soluble TNF- $\alpha$ receptor 1 , which is released at high levels of its ligand TNF- $\alpha$. Plasma concentrations of IL- 6 , but not of soluble TNF- $\alpha$ receptor 1 , were also enhanced after 10 days of sleep restriction to $4 \mathrm{~h}$ per day [55]. Eighty-eight hours of sleep deprivation or 10 days of sleep restriction to $4 \mathrm{~h}$ per night enhanced the concentration of C-reactive protein, an important clinical biomarker of inflammation [84]. Interestingly, even a relatively mild restriction of sleep from 8 to 6 h for 8 days effectively heightened the level of proinflammatory cytokines [122].

Further evidence that prolonged sleep loss is accompanied by enhanced pro-inflammatory activity comes from studies investigating normal ageing and from clinical investigations of patients with chronic sleep disturbances [45, 91, 120]. However, these studies are correlative in nature and thus do not allow for inferences regarding cause-effect relationships. Studies that examined changes in sleep after administration of pro-inflammatory cytokines did not help to clarify this issue, as they did not reveal any uniform effects of these cytokines on sleep, with some cytokines, like IL-1 and TNF- $\alpha$, promoting sleep and SWS, whereas for others, like IL-6, a sleep-disturbing influence cannot be excluded [15, 21, 63, 67, 68, 121].

It is presently unclear in which aspects the increase in pro-inflammatory activity produced by prolonged sleep curtailment differs from that induced during healthy SWS. Some findings, discussed above, suggest that the conditions during SWS specifically support cytokine production required for forming adaptive immune responses whereas enhanced pro-inflammatory activity after prolonged sleep loss might be primarily unspecific, related mainly to cells mediating innate immune responses. Also, the enhanced pro-inflammatory activity emerging with prolonged sleep deprivation does not appear to be effectively counterregulated by anti-inflammatory agents, as observed in the course of sleep. In fact, increases in the anti-inflammatory hormone cortisol that develop after prolonged sleep loss are surprisingly small and transient [108, 110].

Although the enhancement of pro-inflammatory markers accompanying prolonged sleep curtailment is generally small, its persistent nature has nonetheless important clinical implications. This so-called low-grade systemic 
inflammation is associated with a wide variety of serious medical conditions, including type 2 diabetes and cardiovascular disease. Moreover, the increases in inflammatory markers after prolonged sleep loss are usually in the same range as that observed in individuals at risk for developing cardiovascular disease in the future $[87,88]$.

Chronic sleep loss is not only associated with an increase in inflammatory markers but also with immunodeficiency. The immune response to vaccination against influenza virus was diminished after 6 days of restricted sleep [109]. There is also evidence for an enhanced susceptibility to the common cold with poor sleep efficiency [24]. Similar signs of an impaired immune defence were revealed in studies in rats subjected to excessive sleep deprivation. Although prolonged sleep withdrawal resulted in an enhanced proinflammatory state and a general immune activation, the activated immune system was not able to successfully combat invading bacteria and toxins, and rats eventually died from bacteraemia $[42,43]$.

In summary, chronic sleep deprivation can be seen as an unspecific state of chronic stress, which per se impacts immune functions and general health $[27,82,83]$. The adverse effects of chronic sleep deprivation comprise an enhanced risk for various diseases as a consequence of a persistent low-grade systemic inflammation on the one hand, as well as a manifest immunodeficiency characterised by an enhanced susceptibility to infections and a reduced immune response to vaccination on the other hand.

\section{Summary and concluding remarks}

Sleep and the circadian system are strong regulators of immunological processes. The basis of this influence is a bidirectional communication between the central nervous and immune system which is mediated by shared signals (neurotransmitters, hormones and cytokines) and direct innervations of the immune system by the autonomic nervous system. Many immune functions display prominent rhythms in synchrony with the regular 24-h sleep-wake cycle, reflecting the synergistic actions of sleep and the circadian system on these parameters. Differentiated immune cells with immediate effector functions, like cytotoxic NK cells and terminally differentiated CTL, peak during the wake period thus allowing an efficient and fast combat of intruding antigens and reparation of tissue damage, which are more likely to occur during the active phase of the organism. In contrast, undifferentiated or less differentiated cells like naïve and central memory $\mathrm{T}$ cells peak during the night, when the more slowly evolving adaptive immune response is initiated. Nocturnal sleep, and especially SWS prevalent during the early night, promotes the release of GH and prolactin, while anti-inflammatory actions of cortisol and catecholamines are at the lowest levels. The endocrine milieu during early sleep critically supports (1) the interaction between APC and T cells, as evidenced by an enhanced production of IL-12, (2) a shift of the Th1/Th2 cytokine balance towards Th1 cytokines and (3) an increase in Th cell proliferation and (4) probably also facilitates the migration of naïve $T$ cells to lymph nodes. Thereby, the endocrine milieu during early sleep likely promotes the initiation of Th1 immune responses that eventually supports the formation of long-lasting immunological memories. Prolonged sleep curtailment and the accompanying stress response invoke a persistent unspecific production of pro-inflammatory cytokines, best described as chronic low-grade inflammation, and also produce immunodeficiency, which both have detrimental effects on health.

Acknowledgement This work was supported by a grant from the Deutsche Forschungsgemeinschaft (SFB 654-Plasticity and Sleep).

Conflict of interest The authors declare that they have no conflict of interest.

Open Access This article is distributed under the terms of the Creative Commons Attribution Noncommercial License which permits any noncommercial use, distribution, and reproduction in any medium, provided the original author(s) and source are credited.

\section{References}

1. Benedict C, Dimitrov S, Marshall L, Born J (2007) Sleep enhances serum interleukin-7 concentrations in humans. Brain Behav Immun 21:1058-1062

2. Benedict C, Scheller J, Rose-John S, Born J, Marshall L (2009) Enhancing influence of intranasal interleukin-6 on slow-wave activity and memory consolidation during sleep. FASEB J 23:3629-3636

3. Benschop RJ, Rodriguez-Feuerhahn M, Schedlowski M (1996) Catecholamine-induced leukocytosis: early observations, current research, and future directions. Brain Behav Immun 10:77-91

4. Besedovsky HO, del Rey A (1996) Immune-neuro-endocrine interactions: facts and hypotheses. Endocr Rev 17:64-102

5. Besedovsky HO, del Rey A (2011) Central and peripheral cytokines mediate immune-brain connectivity. Neurochem Res 36:1-6

6. Bierwolf C, Struve K, Marshall L, Born J, Fehm HL (1997) Slow wave sleep drives inhibition of pituitary-adrenal secretion in humans. J Neuroendocrinol 9:479-484

7. Blask DE (2009) Melatonin, sleep disturbance and cancer risk. Sleep Med Rev 13:257-264

8. Bollinger T, Bollinger A, Skrum L, Dimitrov S, Lange T, Solbach W (2009) Sleep-dependent activity of $\mathrm{T}$ cells and regulatory T cells. Clin Exp Immunol 155:231-238

9. Bollinger T, Bollinger A, Naujoks J, Lange T, Solbach W (2010) The influence of regulatory $\mathrm{T}$ cells and diurnal hormone rhythms on $\mathrm{T}$ helper cell activity. Immunology 131:488-500

10. Bonacho MG, Cardinali DP, Castrillon P, Cutrera RA, Esquifino AI (2001) Aging-induced changes in 24-h rhythms of mitogenic responses, lymphocyte subset populations and neurotransmitter and amino acid content in rat submaxillary lymph nodes during Freund's adjuvant arthritis. Exp Gerontol 36:267-282

11. Bonnet MH, Arand DL (1995) We are chronically sleep deprived. Sleep 18:908-911 
12. Born J, Fehm HL (1998) Hypothalamus-pituitary-adrenal activity during human sleep: a coordinating role for the limbic hippocampal system. Exp Clin Endocrinol Diabetes 106:153-163

13. Born J, Lange T, Hansen K, Molle M, Fehm HL (1997) Effects of sleep and circadian rhythm on human circulating immune cells. J Immunol 158:4454-4464

14. Brown R, Pang G, Husband AJ, King MG (1989) Suppression of immunity to influenza virus infection in the respiratory tract following sleep disturbance. Reg Immunol 2:321-325

15. Bryant PA, Trinder J, Curtis N (2004) Sick and tired: does sleep have a vital role in the immune system? Nat Rev Immunol 4:457-467

16. Campbell JP, Riddell NE, Burns VE, Turner M, van Zanten JJ, Drayson MT, Bosch JA (2009) Acute exercise mobilises CD8+ T lymphocytes exhibiting an effector-memory phenotype. Brain Behav Immun 23:767-775

17. Cano P, Cardinali DP, Rios-Lugo MJ, Fernandez-Mateos MP, Reyes Toso CF, Esquifino AI (2009) Effect of a high-fat diet on 24-hour pattern of circulating adipocytokines in rats. Obesity (Silver Spring) 17:1866-1871

18. Capuron L, Miller AH (2011) Immune system to brain signaling: neuropsychopharmacological implications. Pharmacol Ther 130:226-238

19. Cardinali DP, Della MV, Selgas L, Esquifino AI (1996) Diurnal rhythm in ornithine decarboxylase activity and noradrenergic and cholinergic markers in rat submaxillary lymph nodes. Brain Res 711:153-162

20. Cardinali DP, Brusco LI, Selgas L, Esquifino AI (1998) Diurnal rhythms in ornithine decarboxylase activity and norepinephrine and acetylcholine synthesis in submaxillary lymph nodes and spleen of young and aged rats during Freund's adjuvant-induced arthritis. Brain Res 789:283-292

21. Chen L, Taishi P, Majde JA, Peterfi Z, Obal F Jr, Krueger JM (2004) The role of nitric oxide synthases in the sleep responses to tumor necrosis factor-alpha. Brain Behav Immun 18:390-398

22. Chikanza IC (1999) Prolactin and neuroimmunomodulation: in vitro and in vivo observations. Ann NY Acad Sci 876:119-130

23. Clevenger CV, Altmann SW, Prystowsky MB (1991) Requirement of nuclear prolactin for interleukin-2-stimulated proliferation of T lymphocytes. Science 253:77-79

24. Cohen S, Doyle WJ, Alper CM, Janicki-Deverts D, Turner RB (2009) Sleep habits and susceptibility to the common cold. Arch Intern Med 169:62-67

25. Cooper MA, Fehniger TA, Caligiuri MA (2001) The biology of human natural killer-cell subsets. Trends Immunol 22:633-640

26. Cox JH, Ford WL (1982) The migration of lymphocytes across specialized vascular endothelium. IV. Prednisolone acts at several points on the recirculation pathways of lymphocytes. Cell Immunol 66:407-422

27. Dhabhar FS (2009) Enhancing versus suppressive effects of stress on immune function: implications for immunoprotection and immunopathology. Neuroimmunomodulation 16:300-317

28. Dickstein JB, Moldofsky H, Lue FA, Hay JB (1999) Intracerebroventricular injection of TNF-alpha promotes sleep and is recovered in cervical lymph. Am J Physiol 276:R1018-R1022

29. Dickstein JB, Hay JB, Lue FA, Moldofsky H (2000) The relationship of lymphocytes in blood and in lymph to sleep/wake states in sheep. Sleep 23:185-190

30. Diekelmann S, Born J (2010) The memory function of sleep. Nat Rev Neurosci 11:114-126

31. Dimitrov S, Lange T, Tieken S, Fehm HL, Born J (2004) Sleep associated regulation of $\mathrm{T}$ helper $1 / \mathrm{T}$ helper 2 cytokine balance in humans. Brain Behav Immun 18:341-348

32. Dimitrov S, Lange $\mathrm{T}$, Benedict $\mathrm{C}$, Nowell MA, Jones SA, Scheller J, Rose-John S, Born J (2006) Sleep enhances IL-6 trans-signaling in humans. FASEB J 20:2174-2176
33. Dimitrov S, Lange T, Nohroudi K, Born J (2007) Number and function of circulating human antigen presenting cells regulated by sleep. Sleep 30:401-411

34. Dimitrov S, Benedict C, Heutling D, Westermann J, Born J, Lange $\mathrm{T}$ (2009) Cortisol and epinephrine control opposing circadian rhythms in T cell subsets. Blood 113(21):5134-5143

35. Dimitrov S, Lange T, Born J (2010) Selective mobilization of cytotoxic leukocytes by epinephrine. J Immunol 184:503-511

36. Dodt C, Breckling U, Derad I, Fehm HL, Born J (1997) Plasma epinephrine and norepinephrine concentrations of healthy humans associated with nighttime sleep and morning arousal. Hypertension 30:71-76

37. Drazen DL, Bilu D, Bilbo SD, Nelson RJ (2001) Melatonin enhancement of splenocyte proliferation is attenuated by luzindole, a melatonin receptor antagonist. Am J Physiol Regul Integr Comp Physiol 280:R1476-R1482

38. Dustin ML, Colman DR (2002) Neural and immunological synaptic relations. Science 298:785-789

39. Elenkov IJ, Kvetnansky R, Hashiramoto A, Bakalov VK, Link AA, Zachman K, Crane M, Jezova D, Rovensky J, Dimitrov MA, Gold PW et al (2008) Low- versus high-baseline epinephrine output shapes opposite innate cytokine profiles: presence of Lewis- and Fischer-like neurohormonal immune phenotypes in humans? J Immunol 181:1737-1745

40. Esquifino AI, Selgas L, Arce A, Maggiore VD, Cardinali DP (1996) Twenty-four-hour rhythms in immune responses in rat submaxillary lymph nodes and spleen: effect of cyclosporine. Brain Behav Immun 10:92-102

41. Esquifino AI, Alvarez MP, Cano P, Chacon F, Reyes Toso CF, Cardinali DP (2004) 24-Hour pattern of circulating prolactin and growth hormone levels and submaxillary lymph node immune responses in growing male rats subjected to social isolation. Endocrine 25:41-48

42. Everson CA (1993) Sustained sleep deprivation impairs host defense. Am J Physiol 265:R1148-R1154

43. Everson CA (2005) Clinical assessment of blood leukocytes, serum cytokines, and serum immunoglobulins as responses to sleep deprivation in laboratory rats. Am J Physiol Regul Integr Comp Physiol 289:R1054-R1063

44. Fox CJ, Hammerman PS, Thompson CB (2005) Fuel feeds function: energy metabolism and the T-cell response. Nat Rev Immunol 5:844-852

45. Franceschi C, Capri M, Monti D, Giunta S, Olivieri F, Sevini F, Panourgia MP, Invidia L, Celani L, Scurti M, Cevenini E et al (2007) Inflammaging and anti-inflammaging: a systemic perspective on aging and longevity emerged from studies in humans. Mech Ageing Dev 128:92-105

46. Gala RR (1991) Prolactin and growth hormone in the regulation of the immune system. Proc Soc Exp Biol Med 198:513-527

47. Gallucci S, Matzinger P (2001) Danger signals: SOS to the immune system. Curr Opin Immunol 13:114-119

48. Geissmann F, Jung S, Littman DR (2003) Blood monocytes consist of two principal subsets with distinct migratory properties. Immunity 19:71-82

49. Grakoui A, Bromley SK, Sumen C, Davis MM, Shaw AS, Allen PM, Dustin ML (1999) The immunological synapse: a molecular machine controlling T cell activation. Science 285:221-227

50. Griffin AC, Whitacre CC (1991) Sex and strain differences in the circadian rhythm fluctuation of endocrine and immune function in the rat: implications for rodent models of autoimmune disease. J Neuroimmunol 35:53-64

51. Grossman Z (1984) Recognition of self and regulation of specificity at the level of cell populations. Immunol Rev 79:119-138

52. Guan Z, Vgontzas AN, Omori T, Peng X, Bixler EO, Fang J (2005) Interleukin-6 levels fluctuate with the light-dark cycle in the brain and peripheral tissues in rats. Brain Behav Immun 19:526-529 
53. Haack M, Kraus T, Schuld A, Dalal M, Koethe D, Pollmacher T (2002) Diurnal variations of interleukin-6 plasma levels are confounded by blood drawing procedures. Psychoneuroendocrinology 27:921-931

54. Haack M, Pollmacher T, Mullington JM (2004) Diurnal and sleep-wake dependent variations of soluble TNF- and IL-2 receptors in healthy volunteers. Brain Behav Immun 18:361-367

55. Haack M, Sanchez E, Mullington JM (2007) Elevated inflammatory markers in response to prolonged sleep restriction are associated with increased pain experience in healthy volunteers. Sleep 30:1145-1152

56. Halberg F (1963) Circadian (about twenty-four-hour) rhythms in experimental medicine. Proc R Soc Med 56:253-257

57. Hattori N (2009) Expression, regulation and biological actions of growth hormone $(\mathrm{GH})$ and ghrelin in the immune system. Growth Horm IGF Res 19:187-197

58. Haus E (2007) Chronobiology in the endocrine system. Adv Drug Deliv Rev 59:985-1014

59. Hayashi M, Shimba S, Tezuka M (2007) Characterization of the molecular clock in mouse peritoneal macrophages. Biol Pharm Bull 30:621-626

60. Irwin M, McClintick J, Costlow C, Fortner M, White J, Gillin JC (1996) Partial night sleep deprivation reduces natural killer and cellular immune responses in humans. FASEB J 10:643-653

61. Jones SA, Richards PJ, Scheller J, Rose-John S (2005) IL-6 transsignaling: the in vivo consequences. J Interferon Cytokine Res 25:241-253

62. Kaminski DA, Randall TD (2010) Adaptive immunity and adipose tissue biology. Trends Immunol 31:384-390

63. Kapsimalis F, Richardson G, Opp MR, Kryger M (2005) Cytokines and normal sleep. Curr Opin Pulm Med 11:481-484

64. Keller M, Mazuch J, Abraham U, Eom GD, Herzog ED, Volk HD, Kramer A, Maier B (2009) A circadian clock in macrophages controls inflammatory immune responses. Proc Natl Acad Sci USA 106:21407-21412

65. Kelley KW, Weigent DA, Kooijman R (2007) Protein hormones and immunity. Brain Behav Immun 21:384-392

66. Kioussis D, Pachnis V (2009) Immune and nervous systems: more than just a superficial similarity? Immunity $31: 705-710$

67. Krueger JM (2008) The role of cytokines in sleep regulation. Curr Pharm Des 14:3408-3416

68. Krueger JM, Walter J, Dinarello CA, Wolff SM, Chedid L (1984) Sleep-promoting effects of endogenous pyrogen (interleukin-1). Am J Physiol 246:R994-R999

69. Krueger JM, Obal F Jr, Fang J (1999) Humoral regulation of physiological sleep: cytokines and GHRH. J Sleep Res 8(Suppl 1):53-59

70. La Cava A, Matarese G (2004) The weight of leptin in immunity. Nat Rev Immunol 4:371-379

71. Lange T and Born J (2011) T cell and antigen presenting cell activity during sleep. In: BrainImmune. http://www.brainimmune.com/index. php?option=com_content\&view $=$ article\&id=343:t-cell-and-antigenpresenting-cell-activity-during-sleep\&catid=78:neurohormonalregulation-of-immunity\&Itemid $=421$. Accessed 31 Oct 2011

72. Lange T, Perras B, Fehm HL, Born J (2003) Sleep enhances the human antibody response to hepatitis A vaccination. Psychosom Med 65:831-835

73. Lange T, Dimitrov S, Fehm HL, Westermann J, Born J (2006) Shift of monocyte function toward cellular immunity during sleep. Arch Intern Med 166:1695-1700

74. Lange T, Dimitrov S, Born J (2010) Effects of sleep and circadian rhythm on the human immune system. Ann NY Acad Sci 1193:48-59

75. Lange T, Dimitrov S, Bollinger T, Diekelmann S, Born J (2011) Sleep after vaccination boosts immunological memory. J Immunol 187:283-290
76. Liu YJ (2005) IPC: professional type 1 interferon-producing cells and plasmacytoid dendritic cell precursors. Annu Rev Immunol 23:275-306

77. Lord GM, Matarese G, Howard JK, Baker RJ, Bloom SR, Lechler RI (1998) Leptin modulates the T-cell immune response and reverses starvation-induced immunosuppression. Nature 394:897-901

78. Lucas D, Battista M, Shi PA, Isola L, Frenette PS (2008) Mobilized hematopoietic stem cell yield depends on speciesspecific circadian timing. Cell Stem Cell 3:364-366

79. Luna-Moreno D, Aguilar-Roblero R, Díaz-Munoz M (2009) Restricted feeding entrains rhythms of inflammation-related factors without promoting an acute-phase response. Chronobiol Int 26:1409-1429

80. Maestroni GJ (2001) Neural regulation of dendritic cell function. Adv Exp Med Biol 495:111-119

81. Matsumoto Y, Mishima K, Satoh K, Tozawa T, Mishima Y, Shimizu T, Hishikawa Y (2001) Total sleep deprivation induces an acute and transient increase in NK cell activity in healthy young volunteers. Sleep 24:804-809

82. McEwen BS (2006) Sleep deprivation as a neurobiologic and physiologic stressor: allostasis and allostatic load. Metabolism 55:S20-S23

83. Meerlo P, Sgoifo A, Suchecki D (2008) Restricted and disrupted sleep: effects on autonomic function, neuroendocrine stress systems and stress responsivity. Sleep Med Rev 12:197-210

84. Meier-Ewert HK, Ridker PM, Rifai N, Regan MM, Price NJ, Dinges DF, Mullington JM (2004) Effect of sleep loss on Creactive protein, an inflammatory marker of cardiovascular risk. J Am Coll Cardiol 43:678-683

85. Mellado M, Llorente M, Rodriguez-Frade JM, Lucas P, Martinez C, del Real G (1998) HIV-1 envelope protein gp120 triggers a Th2 response in mice that shifts to Th1 in the presence of human growth hormone. Vaccine 16:1111-1115

86. Mendez-Ferrer S, Lucas D, Battista M, Frenette PS (2008) Haematopoietic stem cell release is regulated by circadian oscillations. Nature 452:442-447

87. Mullington JM, Haack M, Toth M, Serrador JM, Meier-Ewert HK (2009) Cardiovascular, inflammatory, and metabolic consequences of sleep deprivation. Prog Cardiovasc Dis 51:294-302

88. Mullington JM, Simpson NS, Meier-Ewert HK, Haack M (2010) Sleep loss and inflammation. Best Pract Res Clin Endocrinol Metab 24:775-784

89. Nance DM, Sanders VM (2007) Autonomic innervation and regulation of the immune system (1987-2007). Brain Behav Immun 21:736-745

90. Ottaway CA, Husband AJ (1992) Central nervous system influences on lymphocyte migration. Brain Behav Immun 6:97-116

91. Pavon L, Sandoval-Lopez G, Eugenia HM, Loria F, Estrada I, Perez M, Moreno J, Avila U, Leff P, Anton B, Heinze G (2006) Th2 cytokine response in major depressive disorder patients before treatment. J Neuroimmunol 172:156-165

92. Petrovsky N (2001) Towards a unified model of neuroendocrineimmune interaction. Immunol Cell Biol 79:350-357

93. Radogna F, Diederich M, Ghibelli L (2010) Melatonin: a pleiotropic molecule regulating inflammation. Biochem Pharmacol 80:1844-1852

94. Ransohoff RM (2009) Chemokines and chemokine receptors: standing at the crossroads of immunobiology and neurobiology. Immunity 31:711-721

95. Reis ES, Lange T, Kohl G, Herrmann A, Tschulakow AV, Naujoks J, Born J, Kohl J (2011) Sleep and circadian rhythm regulate circulating complement factors and immunoregulatory properties of C5a. Brain Behav Immun 25(7):14161426 
96. Renegar KB, Floyd RA, Krueger JM (1998) Effects of shortterm sleep deprivation on murine immunity to influenza virus in young adult and senescent mice. Sleep 21:241-248

97. Renegar KB, Crouse D, Floyd RA, Krueger J (2000) Progression of influenza viral infection through the murine respiratory tract: the protective role of sleep deprivation. Sleep 23:859-863

98. Ron-Harel N, Cardon M, Schwartz M (2011) Brain homeostasis is maintained by "danger" signals stimulating a supportive immune response within the brain's borders. Brain Behav Immun 25(5):1036-1043

99. Saint-Mezard P, Chavagnac C, Bosset S, Ionescu M, Peyron E, Kaiserlian D, Nicolas JF, Berard F (2003) Psychological stress exerts an adjuvant effect on skin dendritic cell functions in vivo. J Immunol 171:4073-4080

100. Scheff JD, Calvano SE, Lowry SF, Androulakis IP (2010) Modeling the influence of circadian rhythms on the acute inflammatory response. J Theor Biol 264:1068-1076

101. Schwartz M, Kipnis J (2011) A conceptual revolution in the relationships between the brain and immunity. Brain Behav Immun 25(5):817-819

102. Shearer WT, Reuben JM, Mullington JM, Price NJ, Lee BN, Smith EO, Szuba MP, Van Dongen HP, Dinges DF (2001) Soluble TNF-alpha receptor 1 and IL-6 plasma levels in humans subjected to the sleep deprivation model of spaceflight. J Allergy Clin Immunol 107:165-170

103. Simon C, Gronfier C, Schlienger JL, Brandenberger G (1998) Circadian and ultradian variations of leptin in normal man under continuous enteral nutrition: relationship to sleep and body temperature. J Clin Endocrinol Metab 83:1893-1899

104. Smaniotto S, Ribeiro-Carvalho MM, Dardenne M, Savino W, de Mello-Coelho V (2004) Growth hormone stimulates the selective trafficking of thymic CD4+CD8- emigrants to peripheral lymphoid organs. Neuroimmunomodulation 11:299-306

105. Spangelo BL, Hall NR, Ross PC, Goldstein AL (1987) Stimulation of in vivo antibody production and concanavalinA-induced mouse spleen cell mitogenesis by prolactin. Immunopharmacology 14:11-20

106. Spath-Schwalbe E, Hansen K, Schmidt F, Schrezenmeier H, Marshall L, Burger K, Fehm HL, Born J (1998) Acute effects of recombinant human interleukin- 6 on endocrine and central nervous sleep functions in healthy men. J Clin Endocrinol Metab $83: 1573-1579$

107. Spiegel K, Luthringer R, Follenius M, Schaltenbrand N, Macher JP, Muzet A, Brandenberger G (1995) Temporal relationship between prolactin secretion and slow-wave electroencephalic activity during sleep. Sleep 18:543-548

108. Spiegel K, Leproult R, Van Cauter E (1999) Impact of sleep debt on metabolic and endocrine function. Lancet 354:1435-1439

109. Spiegel K, Sheridan JF, Van Cauter E (2002) Effect of sleep deprivation on response to immunization. JAMA 288:1471-1472

110. Spiegel K, Leproult R, L'hermite-Baleriaux M, Copinschi G, Penev PD, Van CE (2004) Leptin levels are dependent on sleep duration: relationships with sympathovagal balance, carbohydrate regulation, cortisol, and thyrotropin. J Clin Endocrinol Metab 89:5762-5771

111. Stephenson JR, Lee JM, Bailey N, Shepherd AG, Melling J (1991) Adjuvant effect of human growth hormone with an inactivated flavivirus vaccine. J Infect Dis 164:188-191

112. Strainic MG, Liu J, Huang D, An F, Lalli PN, Muqim N, Shapiro VS, Dubyak GR, Heeger PS, Medof ME (2008) Locally produced complement fragments $\mathrm{C} 5 \mathrm{a}$ and $\mathrm{C} 3 \mathrm{a}$ provide both costimulatory and survival signals to naive CD4+ $\mathrm{T}$ cells. Immunity 28:425-435

113. Straub RH, Cutolo M (2007) Circadian rhythms in rheumatoid arthritis: implications for pathophysiology and therapeutic management. Arthritis Rheum 56:399-408

114. Straub RH, Cutolo M, Buttgereit F, Pongratz G (2010) Energy regulation and neuroendocrine-immune control in chronic inflammatory diseases. J Intern Med 267:543-560

115. Suchanek O, Podrazil M, Fischerova B, Bocinska H, Budinsky V, Stejskal D, Spisek R, Bartunkova J, Kolar P (2010) Intensive physical activity increases peripheral blood dendritic cells. Cell Immunol 266:40-45

116. Suzuki S, Toyabe S, Moroda T, Tada T, Tsukahara A, Iiai T, Minagawa M, Maruyama S, Hatakeyama K, Endoh K, Abo T (1997) Circadian rhythm of leucocytes and lymphocytes subsets and its possible correlation with the function of the autonomic nervous system. Clin Exp Immunol 110:500-508

117. Taub DD, Tsarfaty G, Lloyd AR, Durum SK, Longo DL, Murphy WJ (1994) Growth hormone promotes human T cell adhesion and migration to both human and murine matrix proteins in vitro and directly promotes xenogeneic engraftment. J Clin Invest 94:293-300

118. Toth LA, Rehg JE (1998) Effects of sleep deprivation and other stressors on the immune and inflammatory responses of influenza-infected mice. Life Sci 63:701-709

119. Van Cauter E, Plat L, Copinschi G (1998) Interrelations between sleep and the somatotropic axis. Sleep 21:553-566

120. Vgontzas AN, Papanicolaou DA, Bixler EO, Kales A, Tyson K, Chrousos GP (1997) Elevation of plasma cytokines in disorders of excessive daytime sleepiness: role of sleep disturbance and obesity. J Clin Endocrinol Metab 82:1313-1316

121. Vgontzas AN, Papanicolaou DA, Bixler EO, Lotsikas A, Zachman K, Kales A, Prolo P, Wong ML, Licinio J, Gold PW, Hermida RC et al (1999) Circadian interleukin-6 secretion and quantity and depth of sleep. J Clin Endocrinol Metab 84:2603-2607

122. Vgontzas AN, Zoumakis E, Bixler EO, Lin HM, Follett H, Kales A, Chrousos GP (2004) Adverse effects of modest sleep restriction on sleepiness, performance, and inflammatory cytokines. J Clin Endocrinol Metab 89:2119-2126

123. Viswanathan K, Dhabhar FS (2005) Stress-induced enhancement of leukocyte trafficking into sites of surgery or immune activation. Proc Natl Acad Sci USA 102:5808-5813

124. Viswanathan K, Daugherty C, Dhabhar FS (2005) Stress as an endogenous adjuvant: augmentation of the immunization phase of cell-mediated immunity. Int Immunol 17:1059-1069

125. Walsh NP, Gleeson M, Shephard RJ, Gleeson M, Woods JA, Bishop NC, Fleshner M, Green C, Pedersen BK, Hoffman-Goetz L, Rogers CJ et al (2011) Position statement. Part one: immune function and exercise. Exerc Immunol Rev 17:6-63

126. Warnock RA, Askari S, Butcher EC, von Andrian UH (1998) Molecular mechanisms of lymphocyte homing to peripheral lymph nodes. J Exp Med 187:205-216

127. Westermann J, Pabst R (1990) Lymphocyte subsets in the blood: a diagnostic window on the lymphoid system? Immunol Today $11: 406-410$

128. Wilhelm I, Born J, Kudielka BM, Schlotz W, Wust S (2007) Is the cortisol awakening rise a response to awakening? Psychoneuroendocrinology 32:358-366

129. Zager A, Andersen ML, Ruiz FS, Antunes IB, Tufik S (2007) Effects of acute and chronic sleep loss on immune modulation of rats. Am J Physiol Regul Integr Comp Physiol 293:R504-R509 